\title{
Investigation of Genetic Polymorphisms Related to the Outcome of Radiotherapy for Prostate Cancer Patients
}

\author{
Hellen Silva Cintra, ${ }^{1,2}$ Juliana Castro Dourado Pinezi, ${ }^{3,4}$ \\ Graziella Dias Pinheiro Machado, ${ }^{2,4}$ Gustavo Moura de Carvalho, ${ }^{2,3}$ \\ Ana Terra Silva Carvalho, ,2 Thalles Eduardo Dias dos Santos, ${ }^{2,3}$ \\ Ricardo Duarte Marciano, ${ }^{2,3}$ and Renata de Bastos Ascenço Soares ${ }^{1,2,3}$ \\ ${ }^{1}$ Programa de Mestrado em Genética, Pontifícia Universidade Católica de Goiás, Avenida Universitária 1440 Setor Universitário, \\ 74605-010 Goiânia, GO, Brazil \\ ${ }^{2}$ Laboratório de Oncogenética e Radiobiologia, Associação de Combate ao Câncer em Goiás, Rua 239 N.52 Lt.29, \\ Setor Universitário, 74605-070 Goiânia, GO, Brazil \\ ${ }^{3}$ Departamento de Medicina, Pontifícia Universidade Católica de Goiás, Avenida Universitária 1440 Setor Universitário, \\ 74605-010 Goiânia, GO, Brazil \\ ${ }^{4}$ Serviço de Radioterapia, Hospital Araújo Jorge, Associação de Combate ao Câncer em Goiás, Rua 239 N.52 Lt.181, \\ Setor Universitário, 74605-070 Goiânia GO, Brazil \\ Correspondence should be addressed to Renata de Bastos Ascenço Soares; renata.soares@pucgoias.edu.br
}

Received 30 June 2013; Accepted 8 October 2013

Academic Editor: Esperanza Ortega

Copyright ( 2013 Hellen Silva Cintra et al. This is an open access article distributed under the Creative Commons Attribution License, which permits unrestricted use, distribution, and reproduction in any medium, provided the original work is properly cited.

\begin{abstract}
The purpose of this study was to evaluate the association between ATM, TP53 and MDM2 polymorphisms in prostate cancer patients and morbidity after radiotherapy. The presence of ATM (rs1801516), TP53 (rs1042522, rs1800371, rs17878362, rs17883323, and rs35117667), and MDM2 (rs2279744) polymorphisms was assessed by direct sequencing of PCR fragments from 48 patients with histologically proven prostate adenocarcinoma and treated with external beam radiation. The side effects were classified according to the Radiation Therapy Oncology Group (RTOG) score. The results showed no association between clinical characteristics and the development of radiation toxicities $(P>0.05)$. The $\mathrm{C}>\mathrm{T}$ transition in the position 16273 (intron 3) of TP53 (rs35117667) was significantly associated with the risk of acute skin toxicity (OR: $0.0072,95 \%$ CI $0.0002-0.227, P=0.003$ ). The intronic TP53 polymorphism at position 16250 (rs17883323) was associated with chronic urinary toxicity (OR: $0.071,95 \%$ CI $0.006-0.784, P$ $=0.032)$. No significant associations were found for the remaining polymorphisms $(P>0.05)$. The results show that clinical characteristics were not determinant on the developing of radiation sensitivity in prostate cancer patients, and intronic TP53 polymorphisms would be associated with increased acute and chronic radiation toxicities. These observations corroborate the importance of investigating the genetic profile to predict adverse side effects in patients undergoing radiotherapy.
\end{abstract}

\section{Introduction}

Radiotherapy is the most important nonsurgical modality for the curative treatment of cancer. The success of radiotherapy in eradicating a tumor depends mainly on the total radiation dose given, but the tolerance of the normal tissues surrounding the tumor limits this dose. There is a significant variation between patients regarding the severity of toxicity following a given dose of radiotherapy. As a consequence, the dose is submaximal in the majority of the radiotherapy patients [1].
Chronic side effects from radiotherapy are often irreversible and can decrease health-related quality of life as well as limit treatment intensity in radical radiotherapy regimens. Quantification of acute and chronic toxicity is therefore crucial in the assessment of the therapeutic benefit of radiotherapy. Various studies worldwide have attempted to identify common genetic variations associated with the development of radiation toxicity as a step in the process of identifying such a subset of toxicity prone patients $[2,3]$. 
Researchers have long recognized that genetic variation contributes to individual differences in radiotherapy toxicity. Studies among prostate cancer patients have identified single nucleotide polymorphisms (SNP) in candidate genes, mostly involved in the DNA damage response, including ataxiatelangiectasia mutated (ATM), transforming growth factor beta 1 gene (TGFB1), X-ray repair cross-complementing protein 1 gene (XRCC1), X-ray repair cross-complementing protein 3 gene (XRCC3), and superoxide dismutase 2 gene (SOD2) among others that are associated with the development of toxicity in response to radiation therapy [4-7]. One study using a genome-wide approach has also identified variants associated with the development of long term side effects of radiation therapy [8]. Polymorphisms in genes responsible for DNA damage signaling and repair might modulate DNA repair capacity and, therefore, affect cell and tissue response to radiation and influence individual radiosensitivity $[9,10]$.

The tumor suppressor protein p53 encoded by the tumor protein 53 gene (TP53), a key regulator of cellular responses to genotoxic stress, is stabilized and activated after DNA damage [11]. The rapid activation of $\mathrm{p} 53$ by ionizing radiation is largely dependent on the ATM kinase. The protein p53 is phosphorylated by ATM shortly after DNA damage, resulting in enhanced stability and activity of p53 [12,13]. The murine double minute 2 (MDM2) oncoprotein is a pivotal negative regulator of $\mathrm{p} 53$. In response to ionizing radiation, MDM2 undergoes rapid ATM-dependent phosphorylation prior to p53 accumulation. The increase in MDM2 basal levels induces degradation and blockade of transcriptional activity of $\mathrm{p} 53$ protein $[14,15]$.

The functional $\mathrm{p} 53$ polymorphism, characterized by $\mathrm{C}>\mathrm{G}$ change at the second position of codon 72 (rs1042522), results in Arg > Pro amino acid substitution. It has been shown that 72Arg allele may induce apoptosis with faster kinetics than Pro72 allele [16]. On the other hand, the Pro72 variant seems to be more competent in inducing cell cycle arrest and DNA repair [17]. Therefore, Pro72 could be associated with a lower incidence of side effects to radiotherapy by being more efficient in cell cycle arrest allowing repair of radiation-induced damage. The p53 polymorphism at codon 47 (rs1800371) is also functionally significant, since it has been demonstrated that the Ser 47 variant has a decreased ability to induce apoptosis compared with the Pro47 p53 allele [18]. The TP53 PIN3 insertion (rs17878362) was chosen based on a study by Tan et al. 2006 [19], which reported no association between this insertion and the development of radiation toxicity; however, we found that it was important to confirm the lack of association in our study population. The remaining intronic polymorphisms (rs35117667 and rs17883323) were selected because they are located in nearby regions to the studied polymorphisms and also because they have not been evaluated by any study so far.

The MDM2 single-nucleotide polymorphism T309G (rs2279744) is located in the promoter region of MDM2. As demonstrated in a different study, it increases the promoter affinity for the stimulatory protein (Sp) 1, intensifying MDM2 expression, and subsequent attenuation of the p53 pathway [20]. We hypothesized that the increased degradation of p53 by MDM2 could lead to adverse effects of radiation therapy.

Mutations and polymorphisms of the ATM gene have been investigated as possible causes of normal tissue radiation sensitivity in breast cancer patients [21]. Breast cancer patients undergoing radiotherapy presented with a higher incidence of adverse chronic effects (fibrosis) when the exon 39 polymorphism D1853N (rs1801516) were present [21]. ATM protein presents kinase activity induced by ionizing radiation, and it is involved in DNA damage detection and in the control of cell cycle progression [22].

The purpose of this study was to examine the hypothesis that the presence of ATM codon Asp1853Asn (5557G>A) polymorphism (rs1801516), TP53 Pro72Arg (rs1042522), TP53 Pro47Ser (rs1800371), 3 intronic TP53 polymorphisms (rs17878362, rs17883323, and rs35117667), or MDM2 309T $>$ G polymorphism (rs2279744) (Table 1) is predictive for the development of adverse radiotherapy responses among prostate cancer patients. It was hypothesized that polymorphisms in these genes would influence DNA repair capacity, modulating responses to radiation and the risk of acute or chronic radiation-induced side effects. We explored any possible association of acute and chronic skin, urinary, and rectal functional outcomes with ATM and TP53 polymorphisms using the Radiation Therapy Oncology Group (RTOG) morbidity criteria [23].

\section{Materials and Methods}

2.1. Study Population and Case Definition. The present study was performed with patients from the Associação de Combate ao Câncer em Goiás (ACCG) who were recruited between January 2009 and December 2010. The 48 eligible patients had histologically confirmed prostate cancer and underwent conventional external beam radiation therapy with curative intent at the Department of Radiotherapy of Araújo Jorge Hospital in Goiânia, Goiás, Brazil. The treatment was performed using a daily dose of two Grays and high-energy photons (15 MV) to obtain deeper penetration and better dose uniformity.

Patients with metastatic carcinoma were excluded from this study. Patients whose followup was less than 24 months were not included on chronic toxicity evaluations. The study was approved by the internal ethical committee, and all patients agreed to participate in the study by signing an informed consent before the biological sample was collected.

The clinical information of the patients, such as treatment type, radiation dose, pretreatment symptoms, age and comorbidities, such as diabetes and vascular disease and radiationinduced injury, were obtained retrospectively from the medical record of each patient. Acute and chronic radiationrelated toxicities were graded using the European Organization for Research and Treatment of Cancer/Radiation Therapy Oncology Group (EORTC/RTOG) morbidity criteria [23]. Patients who developed RTOG grading level 2 or more were classified as having a high grade (HG) adverse response, and those with RTOG grading level 1 and level 0 responses were classified as low grade (LG) responses. 


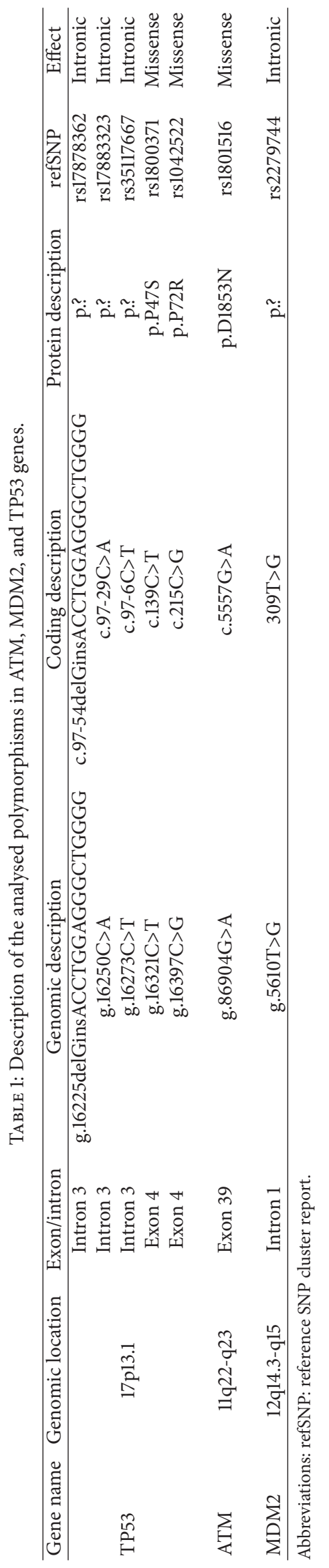


TAble 2: Primer sequences and optimal annealing.

\begin{tabular}{lccc}
\hline Gene name & Primer orientation & Primer sequences $\left(5^{\prime}-3^{\prime}\right)$ & Annealing temperature $\left({ }^{\circ} \mathrm{C}\right)$ \\
\hline \multirow{2}{*}{ TP53 } & Forward & ATGGAGGAGCCGCAGTCAGA & 61.3 \\
& Reverse & TCTGGGAAGGGACAGAAGA & 54.3 \\
ATM & Forward & AGCAGTATGTTGAGTTTATGGC & 60.3 \\
& Reverse & TGAATCCAAGTTTGCAGG & 6 \\
MDM2 & Forward & CGGGAGTTCAGGGTAAAGGT & \\
& Reverse & AGCAAGTCGGTGCTTACCTG & \\
\hline
\end{tabular}

This study used a candidate gene approach to search for associations between genetic variants such as single nucleotide polymorphisms and radiation treatment toxicity.

2.2. Genotyping. For genetic analysis, each patient was approached at the time of follow-up evaluation. A consent form was presented to the patient prior to the collection of their clinical data and blood sample, and all patients included agreed to sign the consent form for this research study. This study was approved by the Ethic's Committee from ACCG.

DNA was isolated from peripheral blood through the iPrep Purification system developed by Invitrogen Corporation, CA, according to the manufacturer's protocol. Polymerase chain reaction (PCR) was used to amplify each fragment using specific primers (Table 2) designed from the genomic sequence obtained from the National Center for Biotechnology Information (http://www.ncbi.nlm.nih.gov/). The optimal annealing temperature for each primer was ascertained experimentally on a gradient PCR machine.

In brief, PCR was performed at a $50 \mu \mathrm{L}$ reaction mixture containing $100 \mathrm{ng}$ of DNA, $10 \mu \mathrm{M}$ of each primer, $0.2 \mu \mathrm{L}$ of Accuprime Taq High Fidelity, and a reaction buffer containing $600 \mathrm{mM}$ Tris- $\mathrm{SO}_{4}, 180 \mathrm{mM}\left(\mathrm{NH}_{4}\right)_{2} \mathrm{SO}_{4}, 20 \mathrm{mM} \mathrm{MgSO}_{4}$, and $2 \mathrm{mM}$ of each deoxynucleoside triphosphate (Invitrogen, CA). The PCR profile consisted of an initial melting step of 10 minutes at $95^{\circ} \mathrm{C}$, followed by 40 cycles of 30 seconds at $95^{\circ} \mathrm{C}, 30$ seconds at $54.3^{\circ} \mathrm{C}$ for ATM, at $61.3^{\circ} \mathrm{C}$ for TP53 or at $60.3^{\circ} \mathrm{C}$ for MDM2 amplification, 1 minute at $72^{\circ} \mathrm{C}$, and a final elongation step of 7 minutes at $72^{\circ} \mathrm{C}$.

The PCR reactions were first subjected to purification using the PureLink Quick Gel Extraction and PCR Purification Combo Kit (Invitrogen, CA), treated with Exo SAPIT (USB Corporation, Cleveland, Ohio, USA) to remove dNTPs and primers and then underwent nucleotide primer extension reaction. The sequencing reactions (BigDye Terminator v. 3.1 Ready Reaction Cycle Sequencing Kit; Applied Biosystems, Foster City, CA) were subjected to purification using BigDye Xterminator (Applied Biosystems, Foster City, CA) for a complete removal of ddNTPs and underwent capillary electrophoresis on an Applied Biosystems 3130xl DNA Analyzer. The data were analysed by the Seqscape Software v2.6 (Applied Biosystems, Foster City, CA).

2.3. Statistical Analysis. Each polymorphism was tested for deviation from Hardy-Weinberg equilibrium by comparing the observed and expected genotype frequencies using the chi-square test with one degree of freedom. Analyses were performed using the SigmaStat version 15.0 statistical software package (SPSS, Inc., Chicago, IL). The association between ATM TP53 and MDM2 polymorphisms and adverse response to radiotherapy was estimated by chi-square test or Fisher's exact test with one degree of freedom. All analyses were performed with $\alpha=5 \%$ and confidence interval of $95 \%$.

\section{Results}

3.1. Patient's Characteristics. Patient's characteristics are described in Table 3. The mean age was 67.3 years. Of 48 patients, $29.2 \%$ had family history of cancer, $47.9 \%$ had hypertension, $12.5 \%$ were diabetic, and $54.2 \%$ had a history of smoking during some time in their lives.

A total of 45 patients (93.7\%) had tumor Gleason score higher than five. 25 patients $(52.1 \%)$ had mean prostate specific antigen (PSA) higher than $10 \mathrm{ng} / \mathrm{mL}$ before treatment and in $77.1 \%$ of the patients, PSA decreased after radiotherapy. Twelve patients (25\%) underwent concomitant hormonal therapy, and seven (14.6\%) had undergone prior prostatectomy. The average radiation dose in the 50 patients was 70.1 Grays (Gy), and the treatment lasted for an average of 61.5 days. The followup ranged from 2 to 92 months.

The patients were classified as having an adverse response, RTOG high grade, or not having an adverse response (RTOG low grade). Tables 4 and 5 show the number of patients having acute or chronic adverse effects of radiotherapy, respectively.

There were no significant differences between patients who developed severe acute or chronic radiation toxicities and those who did not in relation to age, smoking status, Gleason score, family history of cancer, hypertension or diabetes, and radiotherapy dose and patients who underwent concomitant hormonal therapy or had prior prostatectomy $(P>$ 0.05).

\subsection{Polymorphisms and Risk for Development of Radiation} Toxicity. From the initial group of 48 patients eligible for the present study, we analysed polymorphisms in the genes ATM, TP53, and MDM2. For the ATM and MDM2 SNPs, all patients were successfully genotyped. For TP53 gene, we analysed four polymorphisms in the PCR amplified fragment. Complete data was obtained for the TP53 polymorphism at codon 72 . It was possible to verify the presence or absence of this polymorphism in all 48 patients, while data regarding TP53 polymorphisms, at codon 47 and intronic regions 16250 and 16225, were analysed in 47 patients, and region 16273 of intron three was analysed in 46 patients. The frequencies of each polymorphism are shown in Table 6. For Chronic analysis, three patients were excluded because their followup 
TABle 3: Patients clinical characteristics.

\begin{tabular}{|c|c|}
\hline Characteristic & No. of patients (\%) \\
\hline Age (y), median (range) & $67.3(52-82)$ \\
\hline Family history of cancer & $14(29.2)$ \\
\hline Hypertension & $19(39.6)$ \\
\hline Diabetes mellitus & $2(4.2)$ \\
\hline Hypertension + Diabetes mellitus & $4(8.3)$ \\
\hline Other Comorbidities & $6(12.5)$ \\
\hline Any history of smoking & $26(54.2)$ \\
\hline \multicolumn{2}{|l|}{ Gleason score } \\
\hline$\leq 5$ & $3(6.3)$ \\
\hline 6 & $25(52.1)$ \\
\hline 7 & $16(33.3)$ \\
\hline $8-9$ & $4(8.4)$ \\
\hline \multicolumn{2}{|c|}{ PSA (ng/mL) before treatment, no. of patients (PSA range) } \\
\hline$\leq 4$ & $9(0.63-3.80)$ \\
\hline $5-10$ & $14(4.13-10.00)$ \\
\hline $10-20$ & $16(10.60-19.50)$ \\
\hline$>20$ & $9(21.38-151)$ \\
\hline \multicolumn{2}{|l|}{ PSA outcome after radiotherapy } \\
\hline PSA decreased & $37(77.1)$ \\
\hline PSA did not decrease & $11(22.9)$ \\
\hline Concomitant hormonal therapy & $12(25)$ \\
\hline Prior surgery (prostatectomy) & $7(14.6)$ \\
\hline Radiotherapy interruption & $5(10.4)$ \\
\hline Total radiation dose (Gy), median (range) & $70.1(64-74)$ \\
\hline Treatment duration (months), median (range) & $61.5(49-86)$ \\
\hline Follow up (months), median (range) & $48(2-92)$ \\
\hline
\end{tabular}

Abbreviations: PSA: prostate specific antigen; Gy: Grays.

TABLE 4: RTOG acute radiation morbidity (toxicity grading).

\begin{tabular}{lccc}
\hline & Skin RTOG & Lower GI tract RTOG & $n(\%)$ \\
\hline High grade & $n(\%)$ & $n(\%)$ & Urinary RTOG \\
Low grade & $2(4.2)$ & $7(14.6)$ & $23(47.9)$ \\
\hline
\end{tabular}

Abbreviations: RTOG: radiation therapy oncology group; GI tract: gastrointestinal tract.

High grade: RTOG $\geq 2$ e Low grade: RTOG $<2$.

TABLE 5: RTOG chronic radiation morbidity (toxicity grading)* .

\begin{tabular}{lccc}
\hline & Skin RTOG & Lower GI tract RTOG & Urinary tract RTOG \\
& $n(\%)$ & $n(\%)$ & $n(\%)$ \\
\hline High grade & $1(2.2)$ & $2(4.4)$ & $10(22.2)$ \\
Low grade & $44(97.8)$ & $43(95.6)$ & $35(77.8)$ \\
\hline
\end{tabular}

Abbreviations: RTOG: radiation therapy oncology group; GI tract: gastrointestinal tract.

High grade: RTOG $\geq 2$ e Low grade: RTOG $<2$.

* For chronic analyses, it was considered patients with followup higher than 24 months.

was less than 24 months. The frequencies of polymorphisms for chronic associations are shown in Table 7.

In univariate cross-table analysis, the ATM Asp1853Asn polymorphism was not associated with occurrence of either acute or chronic toxicity after radiotherapy $(P>0.05)$. The intronic polymorphism located on region 16273 with a homozygous change of $\mathrm{C}>\mathrm{T}$ was significantly associated to the development of acute skin toxicity RTOG grade two or higher $(\mathrm{OR}=0.0072$, 95\% CI $0.0002-0.227, P=0.003)$ as shown in Table 6 . The heterozygous change of $A>C$ on region 16250 was strongly associated to the developing of chronic urinary toxicity RTOG grade two or higher $(\mathrm{OR}=0.071$, 


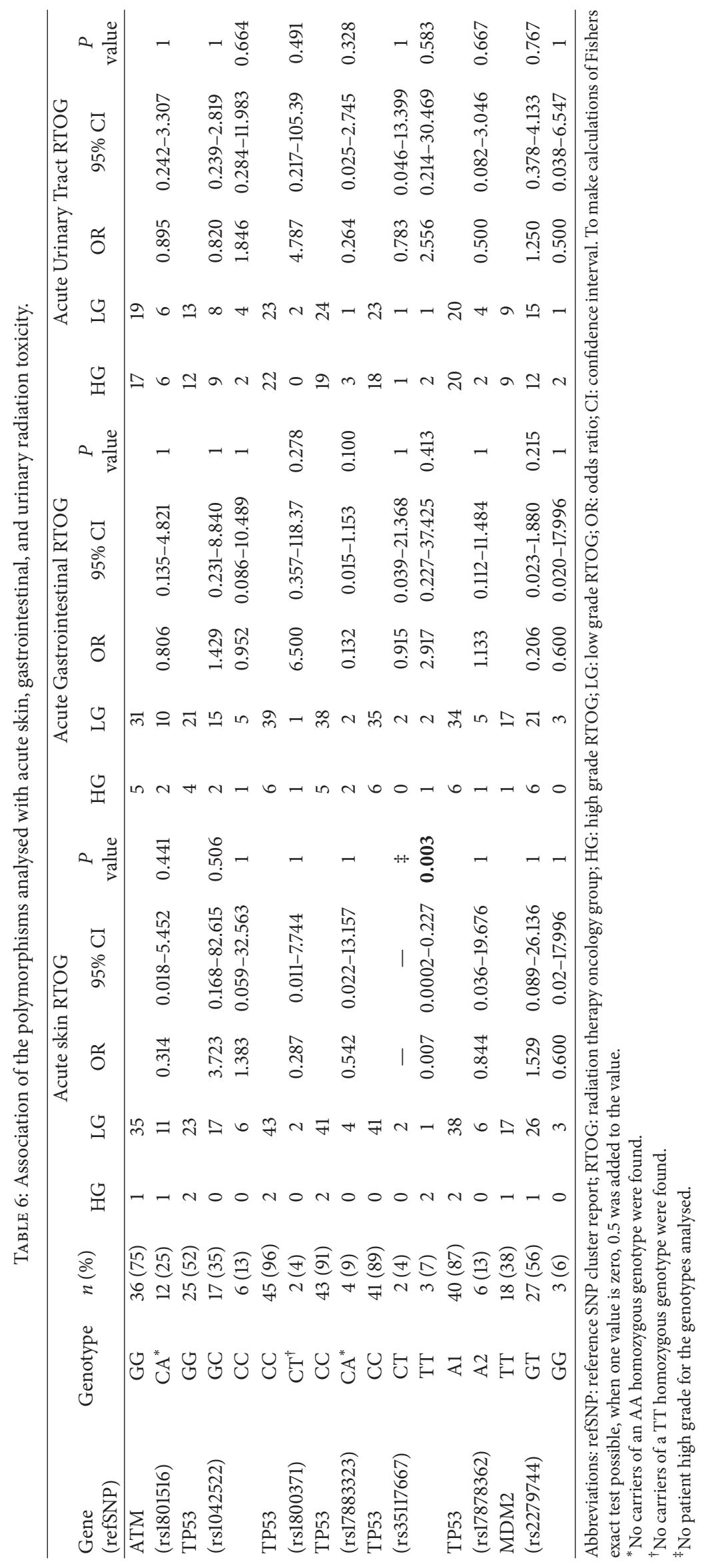




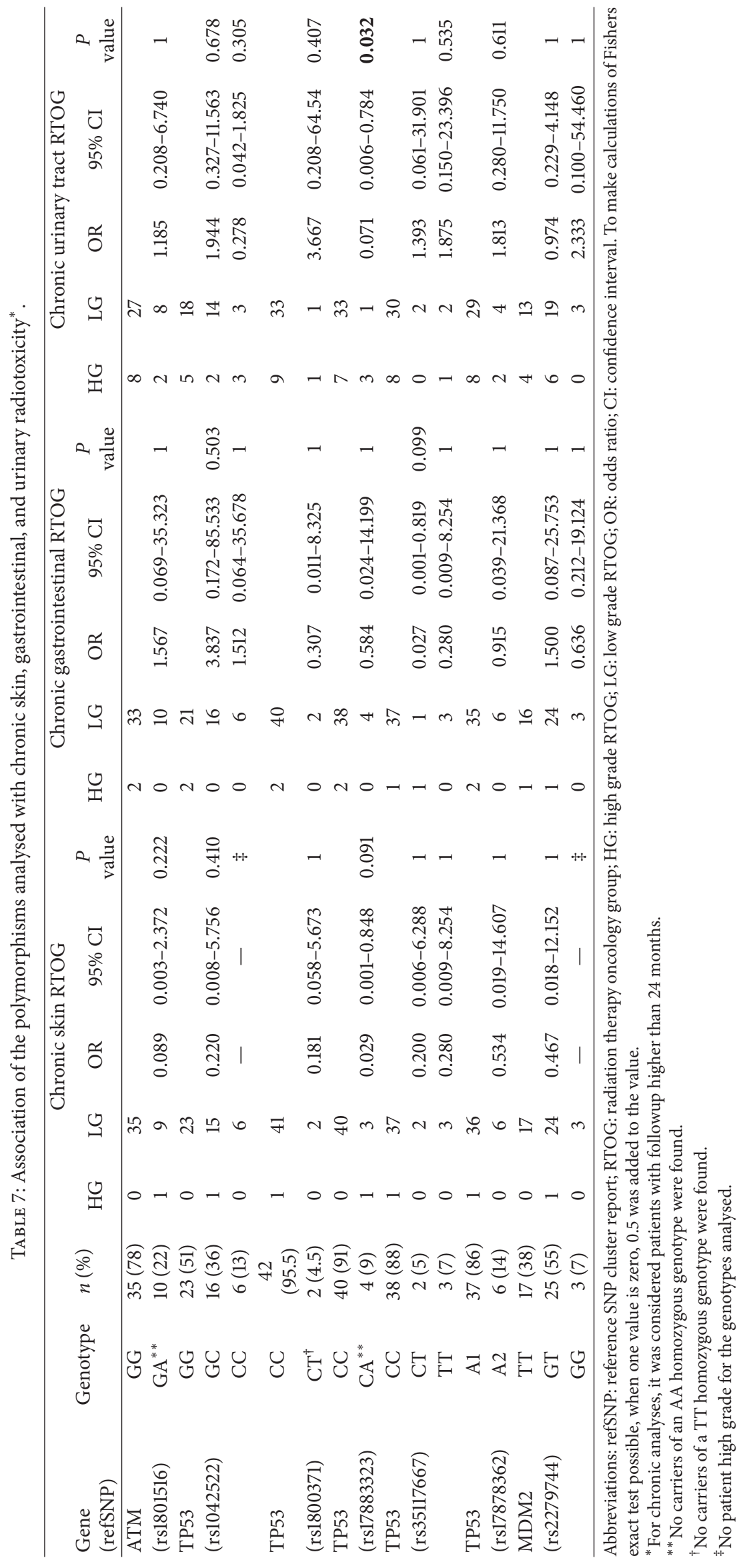


95\% CI 0.006-0.784, $P=0.032$ ). None of the remaining TP53 polymorphisms, including the one located on codon 72 , were significantly associated with the presence of acute or chronic skin, gastrointestinal, and urinary toxicities (Tables 6 and 7).

\section{Discussion}

4.1. Clinical Data Associated with Radiation Toxicity. Our analysis showed, as expected, that clinical features were not determinants of acute or chronic toxicities of the prostate adjacent tissues when submitted to radiotherapy $(P>0.05)$. These results confirm the importance of investigating the genetic profile of patients undergoing radiotherapy in order to find if genetic differences are involved or not involved in the development of radiation toxicities during and after treatment.

4.2. Polymorphisms and Radiation Toxicity. There is a belief that the genomic revolution triggered by full sequencing of the human genome and technological development of large-scale methodologies announces the future of personalized medicine. In oncology, this progress should increase the possibility to predict individual patient responses to radiotherapy and chemotherapy. Andreassen et al. (2002) [24] hypothesized that the radiation sensitivity of normal tissues should be associated with a so-called "trait-dependent complex" which adds the effect of many genetic determinants and single nucleotide polymorphisms that could correspond in part to the frequency and severity of these components.

Some suggestive evidence was obtained from the correlation between the ATM codon Asp1853Asn (5557G>A) SNP and the high risk of the development of radiotherapyinduced acute skin complications in breast cancer patients $[21,25,26]$. For prostate cancer, data are controversial. ATM sequence alterations including codon 1853 polymorphism were associated with the development of radiation-induced proctitis [5], although no relation was shown between this marker and bladder or rectal toxicities arising from the radiation therapy in Canadian prostate cancer patients [27]. Our findings showed that Asp1853Asn polymorphism was not associated with the development of any acute or chronic adverse effects in patients with prostate cancer treated with radiotherapy $(P>0.05)$. ATM is a large gene with many variants documented. Further investigations will be necessary to verify the association of other ATM SNPs in more representative sample groups in order to establish whether single nucleotide polymorphisms or gene haplotypes may actually contribute to the toxicity of normal tissue.

The single base polymorphism in the promoter of MDM2 gene (SNP309; rs2279744) increases gene expression, and it is shown to associate with accelerated tumor formation in both hereditary and sporadic cancers [20]. This SNP creates an improved site of action that regulates basal levels of MDM2. The increase of MDM2 basal levels will also increase the degradation of p53 tumor suppressor protein and may stop its transcriptional activity leading to increased apoptosis [14, $15,28,29]$. The hypothesis that increased apoptosis could cause necrosis of normal tissue leading to radiotherapy side effects was not confirmed by our results. Among the prostate cancer patients of this study, no association of the investigated MDM2 polymorphism (rs2279744) and the incidence of radiotherapy-induced acute and chronic effects were found, thus indicating no major contribution in this cohort of prostate cancer. Similar lack of association was reported by Popanda et al., 2009 [30]. Another study also showed that the MDM2 SNP309 polymorphism was not found to be involved with clinical pathologic variables, recurrence risk, and overall survival outcome in prostate cancer [31].

Many studies have showed the association between the TP53 Pro72Arg polymorphism and cancer susceptibility [3234]. An association between the risk of acute skin toxicity and TP53 Pro72 carriers in those with the CDKN1A 31Ser genotype in a subset of normal weight patients treated with radiotherapy for breast cancer has been shown [19]. Another study found evidence that genetic polymorphisms in the ATM-P53 pathway can influence susceptibility to developing radiation-induced pneumonitis in lung cancer patients after radiotherapy [35]. Despite the strong hypothesis for involvement of this gene, the association between the Pro72Arg polymorphism and the development of normal tissue reaction to radiotherapy in prostate cancer patients has not been fully investigated previously. This was the first study to evaluate the acute and chronic radiation toxicities in patients with prostate cancer and TP53 Pro72Arg polymorphism. No association was found in the studied group, even though 27 (54\%) patients presented the combination Arg/Arg, which has been described as a more predisposed to apoptosis genotype $[16,36]$.

Another polymorphism in TP53 gene, at codon 47 (rs1800371), is also functionally significant. Codon 47 encodes proline in wild type p53, but in a small subset of individuals it can encode a serine. It was showed that the serine 47 variant has up to 5 -fold decreased ability to induce apoptosis compared with wild type p53 [18]. However, on our study, the percentage of patients with this polymorphism was not statistically sufficient to find a relationship with the adverse effects of radiotherapy, even though it is a variant that induces apoptosis. There is no other literature data of association between this polymorphism and toxicity induced by radiation therapy.

Our findings showed that a polymorphism located in the region 16273 of intron 3 of TP53 (rs35117667) was associated with high risk of developing acute skin adverse effects (OR: $0.0072,95 \%$ CI $0.0002-0.227, P=0.003$ ). This polymorphism has not been investigated by any study so far. The present study is the first to observe the frequencies of this polymorphism in a specific population and also the first to associate this polymorphism with radiotherapy. There is also evidence of association between the intronic polymorphism at position 16250 (rs17883323) and chronic high grade toxicity of urinary tract (OR: $0.071,95 \%$ CI $0.006-0.784, P=0.032$ ). This polymorphism has not been previously studied in a clinical population, according to searches on scientific websites. Both intronic polymorphisms (rs35117667 and rs17883323) were validated by genotype data showing minor alleles in at least two chromosomes [37]. It is now necessary to evaluate the molecular basis of the association between these intronic polymorphisms and the risk for radiotherapy side effects. 
An intronic polymorphism is not implicated directly in an altered protein; however, it may lead to alternative splicing or it can be related to MicroRNAs [38-40]. A protein modified by these processes may be associated, for example, an increase of apoptosis.

Gemignani and colleagues [41] in 2004 reported that an insertion/duplication of 16 base pairs in intron 3 of TP53 gene, the so called TP53 PIN3 (rs17878362) described by Lazar et al. [42] (1993), is associated with an increased risk of developing colorectal cancer (OR 1.55, 95\% CI $1: 10$ to $2: 18, P=0.012$ ). Tan et al. [19] (2006) reported no association between the TP53 PIN3 (rs17878362) insertion and the development of adverse effects of radiotherapy $(P>0.05)$. Our data corroborate the results of Tan et al. [19] (2006), which also found no association between this polymorphism and the risk of toxicity after radiotherapy. Our study showed that 42 patients (84\%) had this polymorphism. The frequency of the SNP suggest the importance of a case-control study to assess the association between this polymorphism and the development of prostate cancer, and thus at this stage the functional significance of TP53 PIN3 polymorphism remains poorly explored.

\section{Conclusions}

Until now, most of studies in this field have been carried out using candidate genes, as was done in the present study. These studies can provide valuable information; however, they are limited and have not yet succeeded in providing a predictive test to identify radiosensitivity in patients. In response to lack of success in candidate gene studies and the subsequent recognition that this approach is too limited in scope, radiogenomic investigators have now begun a much broader search to identify genes and SNPs associated with radiation response. Several large-scale genome wide association (GWA) studies have been initiated in which radiotherapy patients are being genotyped for large numbers of common SNPs $[8,43]$.

The results of this study hint to a few candidate genes; however, our study was limited by the small sample size and therefore low statistical power to detect associations. This study shows the importance of genetic investigations as a useful tool for individualization of radiotherapy strategies. It is anticipated that over the next few years, SNPs correlated with susceptibility for the development of adverse effects resulting from radiotherapy will be identified from GWA studies. The data provided by studies in radiogenomics will open new perspectives for interpretation of the results of candidate gene studies such as ours and can be the basis for the development of a predictive assay that may be useful to personalize and optimize cancer treatment.

\section{Acknowledgments}

This work was supported by grants from Financiadora de Estudos e Projetos, FINEP, MCT, Brazil, and Fundação de Amparo a Pesquisa do Estado de Goiás, FAPEG, Brazil. Hellen Cintra had a fellowship from CAPES, MEC, Brazil.
The author would like to thank Dr. Alan George Smulian for the paper revising.

\section{References}

[1] G. C. Barnett, C. M. L. West, A. M. Dunning et al., "Normal tissue reactions to radiotherapy: towards tailoring treatment dose by genotype," Nature Reviews Cancer, vol. 9, no. 2, pp. 134142, 2009.

[2] N. G. Burnet, R. M. Elliott, A. Dunning, and C. M. L. West, "Radiosensitivity, Radiogenomics and RAPPER," Clinical Oncology, vol. 18, no. 7, pp. 525-528, 2006.

[3] C. M. L. West, A. M. Dunning, and B. S. Rosenstein, "Genomewide association studies and prediction of normal tissue toxicity," Seminars in Radiation Oncology, vol. 22, no. 2, pp. 91-99, 2012.

[4] J. A. Cesaretti, R. G. Stock, S. Lehrer et al., "ATM sequence variants are predictive of adverse radiotherapy response among patients treated for prostate cancer," International Journal of Radiation Oncology Biology Physics, vol. 61, no. 1, pp. 196-202, 2005.

[5] J. A. Cesaretti, R. G. Stock, D. P. Atencio et al., "A genetically determined dose-volume histogram predicts for rectal bleeding among patients treated with prostate brachytherapy," International Journal of Radiation Oncology Biology Physics, vol. 68, no. 5, pp. 1410-1416, 2007.

[6] C. A. Peters, R. G. Stock, J. A. Cesaretti et al., "TGFB1 single nucleotide polymorphisms are associated with adverse quality of life in prostate cancer patients treated with radiotherapy," International Journal of Radiation Oncology Biology Physics, vol. 70, no. 3, pp. 752-759, 2008.

[7] R. J. Burri, R. G. Stock, J. A. Cesaretti et al., "Association of single nucleotide polymorphisms in SOD2, XRCC1 and XRCC3 with susceptibility for the development of adverse effects resulting from radiotherapy for prostate cancer," Radiation Research, vol. 170, no. 1, pp. 49-59, 2008.

[8] S. L. Kerns, H. Ostrer, R. Stock et al., "Genome-wide association study to identify single nucleotide polymorphisms (SNPs) associated with the development of erectile dysfunction in African-American men after radiotherapy for prostate cancer," International Journal of Radiation Oncology Biology Physics, vol. 78, no. 5, pp. 1292-1300, 2010.

[9] G. Iliakis, "The role of DNA double strand breaks in ionizing radiation-induced killing of eukaryotic cells," BioEssays, vol. 13, no. 12, pp. 641-648, 1991.

[10] F. Altieri, C. Grillo, M. Maceroni, and S. Chichiarelli, "DNA damage and repair: from molecular mechanisms to health implications," Antioxidants and Redox Signaling, vol. 10, no. 5, pp. 891-937, 2008.

[11] A. J. Levine and M. Oren, "The first 30 years of p53: growing ever more complex," Nature Reviews Cancer, vol. 9, no. 10, pp. 749-758, 2009.

[12] M. B. Kastan and D.-S. Lim, "The many substrates and functions of ATM," Nature Reviews Molecular Cell Biology, vol. 1, no. 3, pp. 179-186, 2000.

[13] A. Tichý, J. Vávrová, J. Pejchal, and M. Rezácová, “Ataxiatelangiectasia mutated kinase $(A T M)$ as a central regulator of radiation-induced DNA damage response," Acta Medica, vol. 53, no. 1, pp. 13-17, 2010.

[14] T. Soussi and K. G. Wiman, "Shaping genetic alterations in human cancer: the p53 mutation paradigm," Cancer Cell, vol. 12, no. 4, pp. 303-312, 2007. 
[15] Y. Levav-Cohen, S. Haupt, and Y. Haupt, " $M d m 2$ in growth signaling and cancer," Growth Factors, vol. 23, no. 3, pp. 183-192, 2005.

[16] P. Dumont, J. I.-J. Leu, A. C. Della Pietra III, D. L. George, and M. Murphy, "The codon 72 polymorphic variants of $\mathrm{p} 53$ have markedly different apoptotic potential," Nature Genetics, vol. 33, no. 3, pp. 357-365, 2003.

[17] D. D. Ørsted, S. E. Bojesen, A. Tybjærg-Hansen, and B. G. Nordestgaard, "Tumor suppressor p53 Arg72Pro polymorphism and longevity, cancer survival, and risk of cancer in the general population," Journal of Experimental Medicine, vol. 204, no. 6, pp. 1295-1301, 2007.

[18] X. Li, P. Dumont, A. Della Pietra, G. Shetler, and M. E. Murphy, "The codon 47 polymorphism in p53 is functionally significant," Journal of Biological Chemistry, vol. 280, no. 25, pp. 2424524251, 2005.

[19] X.-L. Tan, O. Popanda, C. B. Ambrosone et al., "Association between TP53 and p21 genetic polymorphisms and acute side effects of radiotherapy in breast cancer patients," Breast Cancer Research and Treatment, vol. 97, no. 3, pp. 255-262, 2006.

[20] G. L. Bond, W. Hu, E. E. Bond et al., "A single nucleotide polymorphism in the MDM2 promoter attenuates the p53 tumor suppressor pathway and accelerates tumor formation in humans," Cell, vol. 119, no. 5, pp. 591-602, 2004.

[21] A. Y. Ho, G. Fan, D. P. Atencio et al., "Possession of ATM sequence variants as predictor for late normal tissue responses in breast cancer patients treated with radiotherapy," International Journal of Radiation Oncology Biology Physics, vol. 69, no. 3, pp. 677-684, 2007.

[22] C. E. Canman, D.-S. Lim, K. A. Cimprich et al., "Activation of the ATM kinase by ionizing radiation and phosphorylation of p53," Science, vol. 281, no. 5383, pp. 1677-1679, 1998.

[23] J. D. Cox, J. Stetz, and T. F. Pajak, "Toxicity criteria of the Radiation Therapy Oncology Group (RTOG) and the European Organization for Research and Treatment of Cancer (EORTC)," International Journal of Radiation Oncology Biology Physics, vol. 31, no. 5, pp. 1341-1346, 1995.

[24] C. N. Andreassen, J. Alsner, and J. Overgaard, “Does variability in normal tissue reactions after radiotherapy have a genetic basis-where and how to look for it?" Radiotherapy and Oncology, vol. 64, no. 2, pp. 131-140, 2002.

[25] S. Angèle, P. Romestaing, N. Moullan et al., "ATM haplotypes and cellular response to DNA damage: association with breast cancer risk and clinical radiosensitivity," Cancer Research, vol. 63, no. 24, pp. 8717-8725, 2003.

[26] C. N. Andreassen, J. Overgaard, J. Alsner et al., "ATM sequence variants and risk of radiation-induced subcutaneous fibrosis after postmastectomy radiotherapy," International Journal of Radiation Oncology Biology Physics, vol. 64, no. 3, pp. 776-783, 2006.

[27] S. Damaraju, D. Murray, J. Dufour et al., "Association of DNA repair and steroid metabolism gene polymorphisms with clinical late toxicity in patients treated with conformal radiotherapy for prostate cancer," Clinical Cancer Research, vol. 12, no. 8, pp. 2545-2554, 2006.

[28] G. L. Bond, W. Hu, and A. Levine, "A single nucleotide polymorphism in the MDM2 gene: from a molecular and cellular explanation to clinical effect," Cancer Research, vol. 65, no. 13, pp. 5481-5484, 2005.
[29] S. L. Harris, G. Gil, H. Robins et al., "Detection of functional single-nucleotide polymorphisms that affect apoptosis," Proceedings of the National Academy of Sciences of the United States of America, vol. 102, no. 45, pp. 16297-16302, 2005.

[30] O. Popanda, J. U. Marquardt, J. Chang-Claude, and P. Schmezer, "Genetic variation in normal tissue toxicity induced by ionizing radiation," Mutation Research, vol. 667, no. 1-2, pp. 58-69, 2009.

[31] J. J. Jaboin, M. Hwang, C. A. Perez et al., "No evidence for association of the MDM2-309 T/G promoter polymorphism with prostate cancer outcomes," Urologic Oncology, vol. 29, no. 3, pp. 319-323, 2011.

[32] L. Sreeja, V. Syamala, P. B. Raveendran, S. Santhi, J. Madhavan, and R. Ankathil, "p53 Arg72Pro polymorphism predicts survival outcome in lung cancer patients in Indian population," Cancer Investigation, vol. 26, no. 1, pp. 41-46, 2008.

[33] M. B. Parliament and D. Murray, "Single nucleotide polymorphisms of DNA repair genes as predictors of radioresponse," Seminars in Radiation Oncology, vol. 20, no. 4, pp. 232-240, 2010.

[34] T. Pugh, M. Keyes, L. Barclay et al., "Sequence variant discovery in DNA repair genes from radiosensitive and radiotolerant prostate brachytherapy patients," Clinical Cancer Research, vol. 15, no. 15, pp. 5008-5016, 2009.

[35] M. Yang, L. Zhang, N. Bi et al., "Association of P53 and ATM polymorphisms with risk of radiation-induced pneumonitis in lung cancer patients treated with radiotherapy," International Journal of Radiation Oncology Biology Physics, vol. 79, no. 5, pp. 1402-1407, 2011.

[36] G. Alsbeih, N. Al-Harbi, M. Al-Buhairi, K. Al-Hadyan, and M. Al-Hamed, "Association between TP53 codon 72 single-nucleotide polymorphism and radiation sensitivity of human fibroblasts," Radiation Research, vol. 167, no. 5, pp. 535-540, 2007.

[37] M. C. Zody, M. Garber, D. J. Adams et al., "DNA sequence of human chromosome 17 and analysis of rearrangement in the human lineage," Nature, vol. 440, no. 7087, pp. 1045-1049, 2006.

[38] H. I. Suzuki, K. Yamagata, K. Sugimoto, T. Iwamoto, S. Kato, and K. Miyazono, "Modulation of microRNA processing by $\mathrm{p} 53$," Nature, vol. 460, no. 7254, pp. 529-533, 2009.

[39] A. K. L. Leung and P. A. Sharp, "microRNAs: a safeguard against turmoil?” Cell, vol. 130, no. 4, pp. 581-585, 2007.

[40] Z. Peng, Y. Cheng, B. C.-M. Tan et al., "Comprehensive analysis of RNA-Seq data reveals extensive RNA editing in a human transcriptome," Nature Biotechnology, vol. 30, no. 3, pp. 253260, 2012.

[41] F. Gemignani, V. Moreno, S. Landi et al., "A TP53 polymorphism is associated with increased risk of colorectal cancer and with reduced levels of TP53 mRNA," Oncogene, vol. 23, no. 10, pp. 1954-1956, 2004.

[42] V. Lazar, F. Hazard, F. Bertin, N. Janin, D. Bellet, and B. Bressac, "Simple sequence repeat polymorphism within the p53 gene," Oncogene, vol. 8, no. 6, pp. 1703-1705, 1993.

[43] C. West, B. S. Rosenstein, and J. Alsner, "Establishment of a radiogenomics consortium," International Journal of Radiation Oncology, Biology, Physics, vol. 76, no. 5, pp. 1295-1296, 2010. 


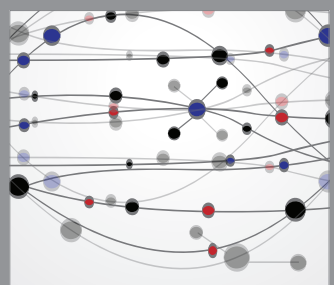

The Scientific World Journal
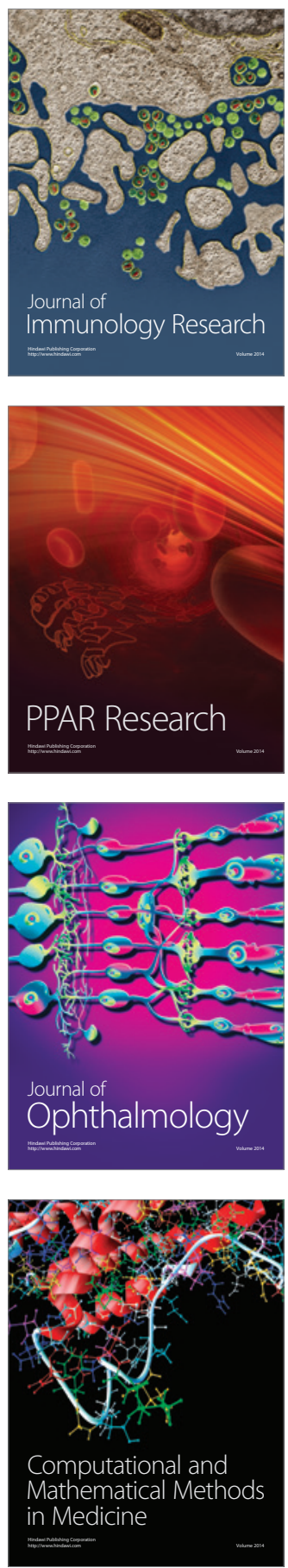

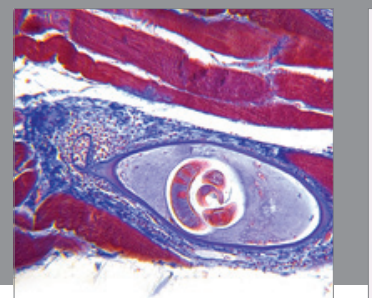

Gastroenterology

Research and Practice
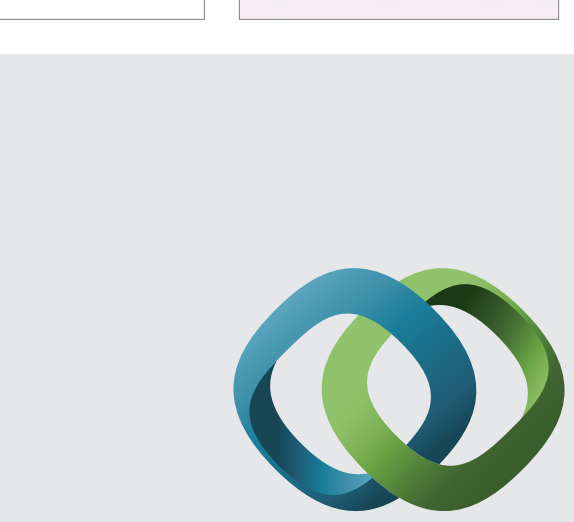

\section{Hindawi}

Submit your manuscripts at

http://www.hindawi.com
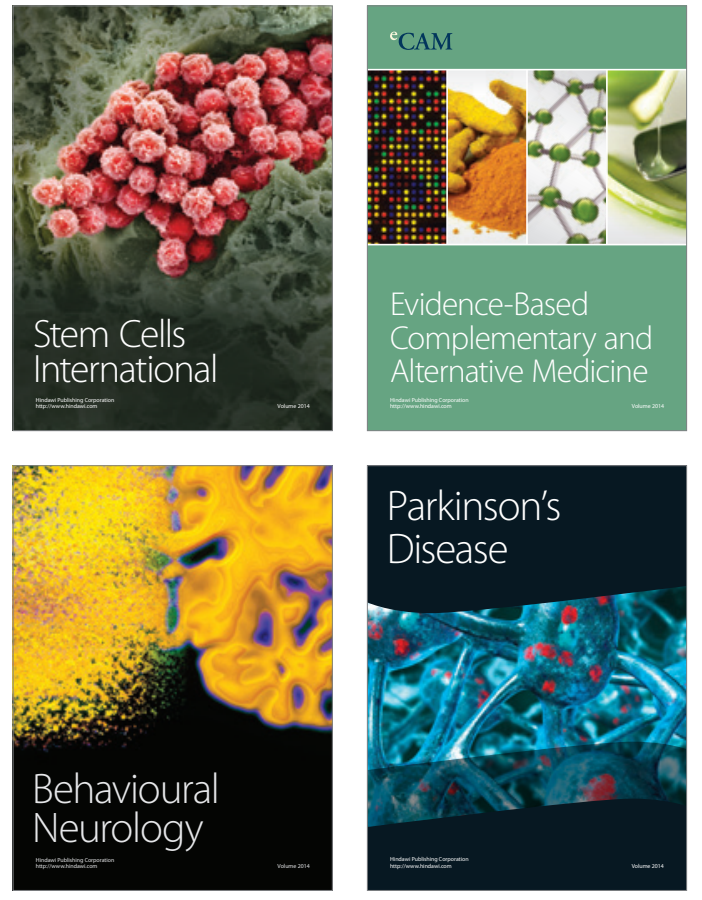
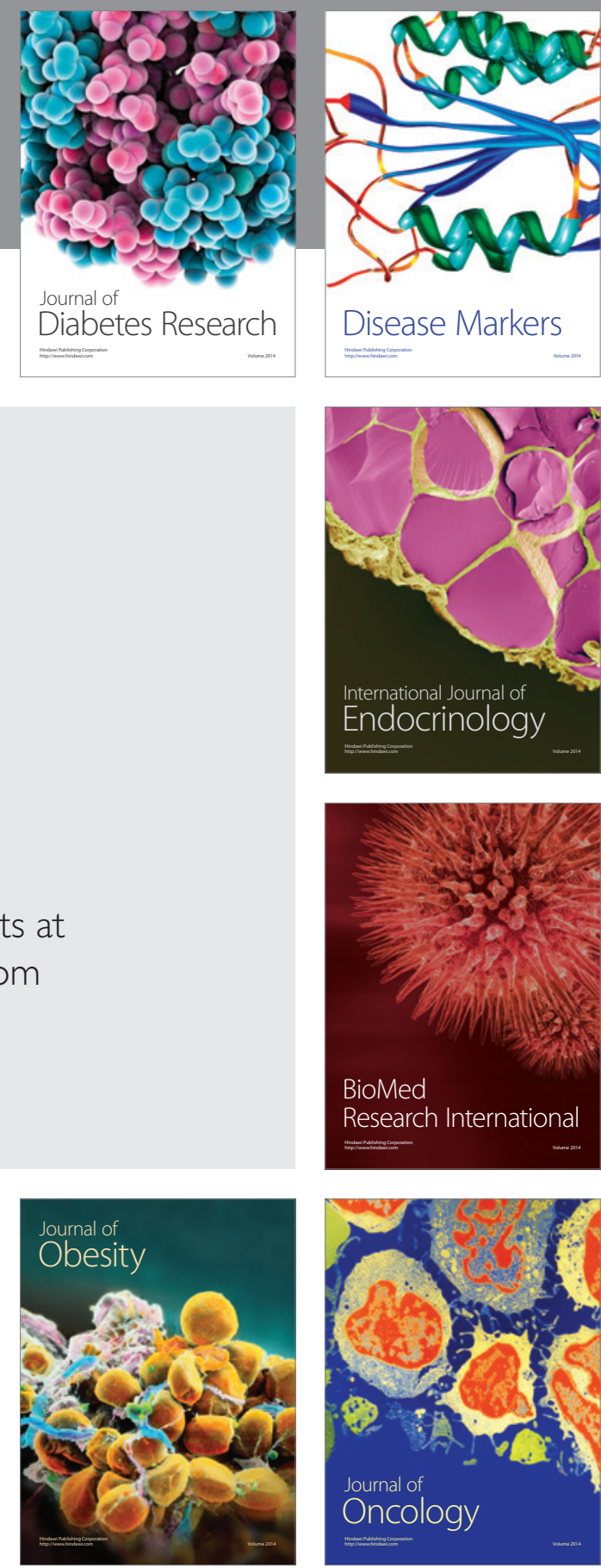

Disease Markers
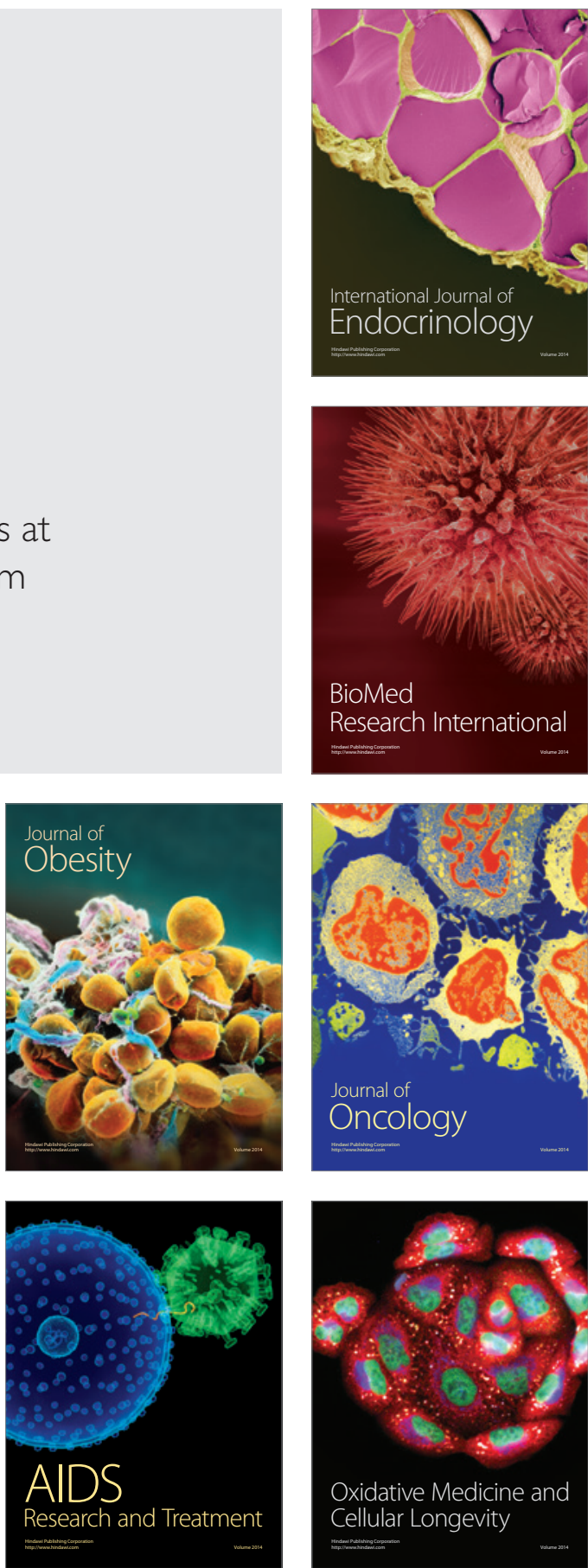